\title{
0305 WEIGHTLIFTING INJURIES IN THE USA: DATA FROM 2000 TO 2008
}

C Jones*, B Hammig, J Henry Correspondence: University of Arkansas, 308K HPER Building, Fayetteville, AR, 72701, USA

10.1136/ip.2010.029215.305

Weightlifting is a popular form of exercise for athletes and nonathletes of all ages. Previous studies suggest weightlifting has low risk for injury. However, the degree for injury may depend on a persons age and the purpose for weightlifting. The purpose of this study is to investigate the current epidemiology of weightlifting injury to determine risk by age and gender and suggest potential environmental or behavioural causes. Methods included obtaining data for the years 2000 through 2008 from the National Electronic Injury Surveillance System using product category 3265 . Estimates are that approximately 650000 injuries related to weightlifting occurred during the study years. Analysis will include the injury environment, diagnosis, intent and body location. The majority of injuries were to males and the mean age was 28. Narratives from the data will be reviewed to determine behavioural and environmental factors that precipitated the injury. Results indicate that weightlifting injuries are still a concern and are increasing. The majority of weightlifting-related injuries are minor but data provide evidence that hospitalisation and death can result from the activity. Children and older adults are high-risk groups for weightlifting injuries. In many accounts, children were bystanders or non-participants when injured. The home was the environment for the majority of injuries, especially to younger groups. Recommendations call for continued education of weightlifting participants in the home as well as in the commercial setting. Manufacturers should continue to consider the development of weightlifting equipment that reduces injury risk and increases safety. 